\title{
Intestinal parasitic infections in children presenting with diarrhoea in outpatient and inpatient settings in an informal settlement of Nairobi, Kenya
}

\author{
Cecilia Kathure Mbae ${ }^{1 *}$, David James Nokes², Erastus Mulinge ${ }^{1}$, Joyce Nyambura ${ }^{1}$, Anthony Waruru $^{3}$ and Samuel Kariuki ${ }^{1}$
}

\begin{abstract}
Background: The distribution of and factors associated with intestinal parasitic infections are poorly defined in high risk vulnerable populations such as urban slums in tropical sub-Saharan Africa.

Methods: In a cross sectional study, children aged 5 years and below who presented with diarrhoea were recruited from selected outpatient clinics in Mukuru informal settlement, and from Mbagathi District hospital, Nairobi, over a period of two years (2010-2011). Stool samples were examined for the presence of parasites using direct, formal-ether concentration method and the Modified Ziehl Neelsen staining technique.

Results: Overall, 541/2112 (25.6\%) were positive for at least one intestinal parasite, with the common parasites being; Entamoeba histolytica, 225 (36.7\%),Cryptosporidium spp. 187, (30.5\%), Giardia lamblia, 98 (16\%). The prevalence of intestinal parasites infection was higher among children from outpatient clinics 432/1577(27.4\%) than among those admitted in hospital 109/535 (20.1\%) p < 0.001. Infections with E. histolytica, and G. lamblia were higher among outpatients than inpatients $(13.8 \%$ vs $1.3 \% p<0.001$ and $5.8 \%$ vs $1.3 \% p<0.049)$ respectively, while infection with Cryptosporidium spp. was higher among inpatients than outpatients ( $15.3 \%$ vs $6.7 \%)$ respectively $p<0.001$. Other parasites isolated among outpatients included Isospora belli, 19 (1.2\%), Ascaris lumbricoides, 26 (1.6\%), and Hymenolepis nana $12(0.8 \%)$, with the remainder detected in less than ten samples each. HIV-infected participants were more likely to be infected with any parasite than uninfected participants, Adjusted Odds Ratio (AOR), 2.04, 95\% $\mathrm{Cl}, 1.55-2.67, \mathrm{p}<0.001$ ), and with Cryptosporidium spp. (AOR, 2.96, 95\% Cl 2.07-4.21, $\mathrm{p}<0.001$ ). The inpatients were less likely to be infected with $E$. histolytica than outpatients (AOR, $0.11,95 \% \mathrm{Cl}, 0.51-0.24, p<0.001$ ), but more likely for inpatients to be infected with Cryptosporidium spp. than outpatients (AOR, 1.91, 95\% Cl, 1.33-2.73, $\mathrm{p}<0.001$ ). Mixed parasitic infections were seen in 65 (12.0\%) of the 541 infected stool samples.
\end{abstract}

Conclusion: Intestinal parasitic infections are common in urban informal settlements' environment. Routine examinations of stool samples and treatment could benefit both the HIV infected and uninfected children in outpatient and inpatient settings.

Keywords: Intestinal parasites, Urban slums, Children, Outpatients, Inpatients

\section{Background}

Seventy three percent of deaths from diarrhoeal illness that occur among children in the developing world are concentrated in just 15 developing countries, including Kenya [1]. It is estimated that some 3.5 billion people are infected, and that 450 million are ill as a result of intestinal parasites and protozoan infections worldwide,

\footnotetext{
* Correspondence: cmkathure@yahoo.com

'Centre for Microbiology Research, P.O Box 19464-00202, Nairobi, Kenya

Full list of author information is available at the end of the article
}

the majority being preschool and school going children [2-4]. Since they commonly occur as mixed intestinal infections, they exacerbate concurrent immunosuppressive conditions such as malnutrition and HIV, and thus, contribute to poor health and impaired cognitive functions [5]. Children from resource-poor countries are more prone to intestinal and extra-intestinal parasitic diseases [6]. Children tend to be more active in the infected environment and rarely employ good sanitary behaviour [7]. Crowding amongst children for example in schools,

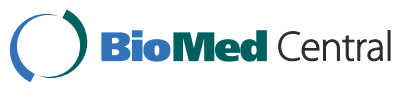


orphanages and poor urban informal settlements, is likely to increase the opportunity for person-to-person transmission or environmental contamination with these parasites [8]. As a result, children who are the primary sufferers, may be an essential vector for the reintroduction of the pathogens to the local environment, hence maintain transmission [9].

Poverty as measured in terms of lack of sanitation, low literacy and overcrowding is associated with parasitic diseases in most communities [10]. In many low and middle-income countries urban migration has led to the creation of urban informal settlements with high rates of polyparasitism with both protozoa and helminths [11-16]. Overcrowding and poor sanitation in these areas lead to higher infection rates through closer proximity of the infected to larger vulnerable populations; parasite transmission thrives in these conditions [17]. Intestinal parasitic infections have enormous consequences on the health of HIV infected patients [18], and sub-Saharan Africa is already over burdened by HIV infection. These patients often suffer from frequent diarrhoeal episodes coupled with weight loss resulting from intestinal parasites, some of which can be fatal [19-22]. Concerted efforts in management of infections in HIV/AIDS patients have targeted diseases such as tuberculosis and other respiratory infections. Less attention has been given to emerging parasitic enteric infections, yet parasites such as Cryptosporidium spp, Isospora belli, Microsporidia spp, Giardia intestinalis, Entamoeba spp., Cyclospora spp., pose unique epidemiological constraints as they are ubiquitous in nature, treatment is still not yet available for some, and others are highly resistant to chlorination and other antiseptics [20]. Previous studies in Kenya have reported high prevalence of intestinal parasites ranging between $12.6 \%$ to $54 \%$ [23-26]. Polyparasitism was frequently observed in all these studies. To the best of our knowledge, there is no published data on the prevalence of intestinal parasitic infections in the informal settlements in Nairobi. Such data underlie decisions on the need for early diagnosis and management in order to prevent the health complications among vulnerable groups such as children, some of who could be HIV positive. In this study we examined the prevalence of intestinal parasitic infections among children aged 5 years and below, both HIV positive and HIV negative, living in Mukuru urban informal settlement, and either presenting at outpatient clinics, or admitted to the Mbagathi District hospital in Nairobi.

\section{Methods}

\section{Study site and patients}

This was a prospective cross sectional study of children aged 5 years and below who presented with diarrhoea to selected outpatient clinics (Reuben Centre, Lea toto and Medical Missionaries of Mary) which, are the only public dispensaries located in Mukuru informal settlement, as well as those admitted to the paediatric wards at Mbagathi District hospital from January 2010 to December 2011. Mukuru informal settlement is situated about $15 \mathrm{~km}$ east of the Nairobi city centre while Mbagathi District hospital is $5 \mathrm{~km}$ to the west of centre, and both serve patients from the slums and other low income areas from these locales. An episode of diarrhoea was defined as three or more loose bowel movements over a 24-hour period prior to the day of presentation. Basic demographic information including age, sex, and residence was collected on enrolment using a structured questionnaire. Consent was obtained from parents or guardians, after which counselling and testing for HIV was offered by qualified personnel as per the National guidelines [27]. Those children who tested HIV positive were referred to the comprehensive care centres within the study clinics and the Mbagathi District hospital for further management. The rainfall patterns for the study period, i.e. 2010-2011 were obtained from the Meteorological Department in Nairobi. The study was approved by the Kenya National Ethical Review Committee. All guardians of participating children were informed of the study objectives and voluntary consent was sought before inclusion. All laboratory results were included in the patients' reports to the clinicians for appropriate management. The samples were examined for enteric parasitic infections, and were not analysed for viral or bacterial infections.

\section{Laboratory procedures}

HIV testing was performed according to the Kenyan National Policy for all paediatric hospital admissions [27]. Specially formulated absorbent filter papers were used for collecting a drop of blood for infants under 18 months of age for molecular diagnosis through PCR [28]. Children aged 18 months or older were tested using two rapid antibody tests: Determine (Inverness Medical, USA) and Unigold (Trinity Biotech, Ireland). Fresh stool samples from children who met the inclusion criteria and enrolled in the study, were collected in clean polypots and labelled with a unique identifier. They were examined macroscopically for consistency, mucus, blood, and microscopically for the presence of ova, larvae, trophozoites and cysts of intestinal and extra-intestinal parasites. Stool examinations were performed by direct method and the formal-ether concentration techniques as described by Cheesbough [29]. Smears from the concentrates were stained using Modified Ziehl-Neelsen staining technique as described by Casemore [30], for identification of Cryptosporidium spp. and other protozoa. 


\section{Data processing and analysis}

Data from questionnaires was entered into a Microsoft Access database using EpiInfo ${ }^{\mathrm{Tm}}$ version 3.3 [31]. Data cleaning procedures were performed before importing data for analysis into Stata 9.2 (Stata Corporation, Texas USA). Frequencies, proportions, medians and interquartile ranges (IQR) were used to describe the study population and parasitic infection. A Fisher's exact chi-square test used to compare proportions. Non-parametric equality of medians test was used to compare medians. Logistic regression to identify potential correlates of infection with any parasite, and infection with each of the 3 most common parasites, and included all factors included in the unadjusted analysis in multivariate logistic regression models to determine significant and independent correlates of parasitic infection. Odds ratios were used to describe associations and a p-value of $<0.05$ was considered significant.

\section{Results}

A total of 2,112 stool samples from children aged 5 years and below were collected for the study of which 1577 (75\%) were from outpatient clinics in Mukuru informal settlements, and 535 (25\%) were from children admitted to the paediatric ward at the Mbagathi District Hospital. Overall, 1116 (52.8\%) were male and 996 (47.2\%) were female. Sixteen children, who were eligible and were consented, did not give stool samples while 40 children were eligible but their parents/guardians declined to give consent. All were from the outpatient clinics.The median age of the children was 18 months (IQR: 9 to 32 months). Outpatients were older than inpatients: 24 months (IQR: 12 to 36 months) versus 10 months (IQR: 7 to 14 months), $\mathrm{p}<0.001$. On microscopic examination of stool samples $541(25.6 \%)$ of all samples analysed were positive for at least one intestinal parasite. The prevalence of intestinal parasites was 613/1577 (38.9\%), among children from outpatient clinics and 113/ 535 (21.1\%) among those admitted in hospital. In total, fifteen types of parasites were isolated from children presenting at the outpatient clinics, with the three most common ones being E. histolytica, 218 (13.8\%), Cryptosporidium spp. 105 (6.7\%), G.lamblia, 91 (5.8\%). Other parasites isolated include; A.lumbricoides, 26 (1.6\%), I.belli,19 (1.2\%), H.nana 12 (0.8\%), while others including C. mesnili, E. coli, H. diminuta, T. trichiura, Taenia spp, hookworms, Cyclospora, E. vermicularis and S. mansoni were detected in less than 10 samples each, and contributed to $5 \%$ of all infections. Among inpatients, Cryptosporidium spp.,82/535 (15.3\%) was the most common parasite, followed by I. belli, 16 (3.0\%) while G.lamblia and E. histolytica were less common each with a prevalence of $1.3 \%$, and Cyclospora which was detected in one sample $(0.2 \%)$ (Table 1$)$. Polyparasitism was observed in $65(12.0 \%)$ of the 541 infected stool samples, details of this data are not shown.

\section{Associations of patient characteristics and infection with 3 common parasites a) Entamoeba histolytica}

In univariate analysis, gender, patient age, and patient type were individually associated with $E$. histolytica infection. Females were less likely to be infected (OR 0.74, 95\% CI 0.56-0.98) $\mathrm{p}=0.033$. Children aged 13-24, 25$36,37-48$ and $49-60$ months were more likely to be infected with $E$. histolytica compared to those up to 12 months old with 37-48 having highest odds (OR 1.86, 95\% CI 1.22-2.84 p=0.004; OR 3.0, 95\% CI 1.984.53, $\mathrm{p}<0.001$; OR 4.02, 95\% CI 2.57-6.29, $\mathrm{p}<0.001$; and OR 3.3, 95\% CI 01.93-5.64, $\mathrm{p}=0.033$, respectively), (Table 2). Inpatients were less likely to be infected with E. histolytica than outpatients, (OR 0.83, 95\% CI 0.04$0.18, \mathrm{p}<0.001)$, while there was no significant difference in E. histolytica infections between HIV positive and HIV negative children $\mathrm{p}=0.225$, (Table 2). In multivariate analysis, infection with $E$. histolytica infection was associated with gender, age and HIV status. Female children were more likely to be infected with $E$. histolytica infection than male children (AOR, 0.68; 95\% CI 0.510.92, $\mathrm{p}=0.012$ ). Children older than 24 months were more likely to get the infection, compared to children aged up to 12 months (AOR, 2.04; 95\% CI 1.31-3.19, $\mathrm{p}=0.002),(\mathrm{AOR}, 2.55 ; 95 \% \mathrm{CI} 1.59-4.13, \mathrm{p}<0.001)$ and (AOR, 1.96; 95\% CI 1.12- 3.43, $\mathrm{p}=0.019$ ) for age groups 25 to 36,37 to 48 and 49 to 60 months, respectively. The HIV seropositive children were also more likely to get infected with $\mathrm{E}$. histolytica than HIV seronegative children, (AOR, 1.58; 95\% CI 1.182.33, $\mathrm{p}=0.019)$. Inpatients were less likely to get the infection than outpatients (AOR, 0.11; 95\% CI 0.51$0.24, \mathrm{p}<0.001)$, while there was no significant difference in these infections between wet and dry seasons $(\mathrm{p}=0.769)$ (Table 2).

\section{b) Cryptosporidium spp}

For Cryptosporidiosis, univariate analysis did not show any significant differences in infection between males and females, $\mathrm{p}=0.977$, however, HIV seropositive children were three times more likely to be infected with Cryptosporidium spp. than the HIV seronegative ones (OR 3.07, 95\% CI 2.19-4.32) $\mathrm{p}<0.001$. Age was also found to be significantly associated with Cryptosporidium spp. infection, whereby the prevalence was highest in children aged 13-24 months at $14.2 \%$, this was the age group that was more likely to acquire cryptosporidiosis [(OR 1.49, CI, 1.06-2.09), $\mathrm{p}=0.023$ ]. Inpatients were equally more than twice at risk of cryptosporidium infection than outpatients [(OR 2.54, CI, 1.87-3.45), 
Table 1 Patient characteristics by patient type, ( inpatient or outpatient), for children with diarrhoea aged 5 years and below, recruited to a study of intestinal parasites in urban poor, Nairobi, between January 2010 and December 2011

\begin{tabular}{|c|c|c|c|c|c|c|c|}
\hline Patient characteristics & Total & (\%) & Out-patient & (\%) & In-patient & (\%) & p-value \\
\hline Total & 2112 & 100 & 1577 & 100 & 535 & 100 & - \\
\hline \multicolumn{8}{|l|}{ Sex } \\
\hline Male & 1116 & 52.8 & 813 & $(51.6)$ & 303 & $(56.6)$ & 0.045 \\
\hline Female & 996 & 47.2 & 764 & $(48.4)$ & 232 & $(43.4)$ & \\
\hline \multicolumn{8}{|l|}{ Age group ${ }^{1}$} \\
\hline 0 to 12 months & 758 & 36.4 & 402 & $(26.0)$ & 356 & $(66.5)$ & $<0.001^{*}$ \\
\hline 13 to 24 months & 528 & 25.3 & 387 & $(25.0)$ & 141 & $(26.4)$ & 0.564 \\
\hline 25 to 36 months & 408 & 19.6 & 377 & $(24.4)$ & 31 & $(5.8)$ & $<0.001^{*}$ \\
\hline 37 to 48 months & 241 & 11.6 & 237 & $(15.3)$ & 4 & $(0.7)$ & $<0.001^{*}$ \\
\hline 49 to 60 months & 148 & 7.1 & 145 & $(9.4)$ & 3 & $(0.6)$ & $<0.001^{*}$ \\
\hline \multicolumn{8}{|l|}{ Parasites infection } \\
\hline E. Hystolytica & 225 & 10.7 & 218 & $(13.8)$ & 7 & $(1.3)$ & $<0.001^{*}$ \\
\hline Cryptosporidium spp. & 187 & 8.9 & 105 & $(6.7)$ & 82 & $(15.3)$ & $<0.001^{*}$ \\
\hline G. lamblia & 98 & 4.6 & 91 & (5.8) & 7 & $(1.3)$ & $<0.001^{*}$ \\
\hline I. belli & 35 & 1.7 & 19 & $(1.2)$ & 16 & (3) & $0.009^{*}$ \\
\hline A. lumbricoides & 26 & 1.2 & 26 & (1.6) & 0 & (0) & $0.001^{*}$ \\
\hline H. nana & 12 & 0.6 & 12 & $(0.8)$ & 0 & (0) & $0.045^{*}$ \\
\hline C. mesnili & 7 & 0.3 & 7 & $(0.4)$ & 0 & $(0)$ & 0.202 \\
\hline E. coli & 6 & 0.3 & 6 & $(0.4)$ & 0 & (0) & 0.347 \\
\hline H. diminuta & 4 & 0.2 & 4 & $(0.3)$ & 0 & (0) & 0.578 \\
\hline T. trichiura & 3 & 0.1 & 3 & $(0.2)$ & 0 & (0) & 0.576 \\
\hline Taenia spp. & 3 & 0.1 & 3 & $(0.2)$ & 0 & (0) & 0.576 \\
\hline Hookworms & 2 & 0.1 & 2 & $(0.1)$ & 0 & (0) & 1.000 \\
\hline Cyclospora & 2 & 0.1 & 1 & $(0.1)$ & 1 & $(0.2)$ & 0.443 \\
\hline E. vermicularis & 2 & 0.1 & 2 & $(0.1)$ & 0 & $(0)$ & 1.000 \\
\hline S. mansoni & 1 & 0 & 1 & $(0.1)$ & 0 & (0) & 1.000 \\
\hline \multicolumn{8}{|l|}{ Infected with any parasite } \\
\hline Yes & 541 & $(25.6)$ & 432 & $(27.4)$ & 109 & $(20.4)$ & \\
\hline No & 1571 & $(74.4)$ & 1145 & $(72.6)$ & 426 & (79.6) & $0.001^{*}$ \\
\hline \multicolumn{8}{|l|}{ HIV Status ${ }^{2}$} \\
\hline Negative & 1598 & 84.1 & 1226 & $(85.4)$ & 372 & $(80.2)$ & $0.009^{*}$ \\
\hline Positive & 302 & 15.9 & 210 & $(14.6)$ & 92 & (19.8) & \\
\hline
\end{tabular}

KEY: *significant, missing values $1=29 ; 2=212$.

$\mathrm{p}<0.001]$. In multivariate analysis, Cryptosporidium spp. infection was significantly associated with age groups 13 to 24 more likely to get the infection (AOR, 1.90, $\mathrm{CI}, 1.31-2.75, \mathrm{p}<0.001$ ), and 37 to 48 months group was inversely associated with Cryptosporidiosis (AOR, 0.39, 95\% CI, 0.16-0.93, $\mathrm{p}=0.034$ ) as compared to children up to 12 months old. Positive HIV status and being an inpatient, was significantly associated with Cryptosporidiosis (AOR, 2.96, 95\% CI, 2.07-4.21, $\mathrm{p}<0.001$ ) and (AOR; 1.91, 95\% CI, 1.33-2.73, $\mathrm{p}<0.001$ ) respectively. Both univariate and multivariate analysis showed that cryptosporidiosis was seasonal with more infections occurring during wet the season [(OR 1.72, CI, 1.23-2.41), $\mathrm{p}<0.001$; AOR, 1.45, CI,1.01-2.09, $\mathrm{p}=0.042$ ] (Table 3, Figure 1).

\section{c) Giardia lamblia}

In unadjusted analysis, children in age group 13 to 24 months were approximately 3 times more likely to be infected with $G$. lamblia than children below 13 months old (OR, 3.41, 95\% CI, 1.61-7.22, $\mathrm{p}=0.001$ ), while children in age group 25 to 36 months were 5 times 
Table 2 Associations between patient characteristics and parasitic infection for children aged 5 years and below with diarrhoea in a study of intestinal parasites in urban poor, Nairobi, January 2010 to December 2011

\begin{tabular}{|c|c|c|c|c|c|c|c|}
\hline \multirow{2}{*}{ Patient characteristics } & \multirow{2}{*}{ E. histolytica (\%) } & \multicolumn{3}{|c|}{ Crude } & \multicolumn{3}{|c|}{ Adjusted } \\
\hline & & OR & $95 \% \mathrm{Cl}$ & p-value & AOR & $95 \% \mathrm{Cl}$ & $\mathrm{p}$-value \\
\hline Total & $225 / 2112(10.7)$ & - & - & - & - & - & - \\
\hline \multicolumn{8}{|l|}{ Gender } \\
\hline Male (ref) & 134/1116(12) & 1.0 & - & - & 1.0 & - & - \\
\hline Female & 91/996(9.1) & 0.74 & $0.56,0.98$ & $0.033^{*}$ & 0.68 & $0.51,0.92$ & $0.012^{*}$ \\
\hline \multicolumn{8}{|l|}{ Age group ${ }^{1}$} \\
\hline 0 to 12 months (ref) & $42 / 758(5.5)$ & 1.0 & - & - & 1.0 & - & - \\
\hline 13 to 24 months & $52 / 528(9.8)$ & 1.86 & $1.22,2.84$ & $0.004^{*}$ & 1.46 & $0.93,2.28$ & 0.098 \\
\hline 25 to 36 months & $61 / 408(15)$ & 3.0 & $1.98,4.53$ & $<0.001^{*}$ & 2.04 & $1.31,3.19$ & $0.002^{*}$ \\
\hline 37 to 48 months & 46/241(19.1) & 4.02 & $2.57,6.29$ & $<0.001^{*}$ & 2.55 & $1.59,4.13$ & $<0.001^{*}$ \\
\hline 49 to 60 months & 24/148(16.2) & 3.3 & $1.93,5.64$ & $<0.001^{*}$ & 1.96 & $1.12,3.43$ & $0.019^{*}$ \\
\hline \multicolumn{8}{|l|}{ HIV status ${ }^{2}$} \\
\hline Negative (ref) & 178/1598(11.1) & 1.0 & - & - & 1.0 & - & - \\
\hline Positive & 41/302(13.6) & 1.25 & $0.87,1.80$ & 0.225 & 1.58 & $1.18,2.33$ & $0.019^{*}$ \\
\hline \multicolumn{8}{|l|}{ Patient type } \\
\hline Outpatients (ref) & 218/1577(13.8) & 1.0 & - & - & 1.0 & - & - \\
\hline Inpatients & $7 / 535(1.3)$ & 0.83 & $0.04,0.18$ & $<0.001^{*}$ & 0.11 & $0.51,0.24$ & $<0.001^{*}$ \\
\hline Seasonality & & & - & - & & & \\
\hline Dry Season (ref) & & 1.0 & - & - & 1.0 & - & - \\
\hline Wet season & & 0.96 & $0.72,1.27$ & 0.769 & 1.29 & $0.96,1.74$ & 0.096 \\
\hline
\end{tabular}

KEY: *significant, missing values $1=29 ; 2=212$.

Infection with Entamoeba histolytica.

more likely to get the infection than children below 13 months old (OR, 5.10, 95\% CI, 2.43-10.67, p < 0.001). Infections with $G$. lamblia, just like with $E$. histolytica were highest in 37-48 months age group at $10.8 \%$, and the children in this age group were more than twice as likely to get infected compared to those below 13 months old, (OR, 9.05, 95\% CI, 4.30-19.05), $\mathrm{p}<0.001)$. The odds for giardiasis among children between 49 and 60 months old was 7.20, 95\% CI, 3.10$16.76, \mathrm{p}<0.001$. Inpatients were less likely to acquire giardiasis than outpatients, [OR, $0.22,95 \% \mathrm{CI}, 0.10$ $0.47), \mathrm{p}<0.001)]$. There were no significant associations between Giardia infections and gender $(\mathrm{p}=0.383)$, and HIV status $(\mathrm{p}=0.497)$. In adjusted analysis, giardiasis was not associated with gender $(p=0.193)$, and HIV status $(\mathrm{p}=0.946)$ but was significantly associated with age groups 13-24, 25-36, 37-48 and 49-60 months compared with children up to 12 months old, (AOR, 2.36, 95\% CI, 1.07-5.14, $\mathrm{p}=0.033$ ), (AOR, 3.26, 95\% CI, 1.49-7.13, $\mathrm{p}=0.003)$, (AOR, 5.86, 95\% CI, 2.67-12.89, $\mathrm{p}<0.001$ ), (AOR, 3.95, 95\% CI, 1.59-9.78, $\mathrm{p}<0.003$ ), respectively. Inpatients were less likely to get the infection than outpatients (AOR, 0.41, 95\% CI, 0.17-1.00, p = 0.049), (Table 4).

\section{Associations of patient characteristics and infection with any parasite}

Infection with any parasite was highest among children in age group 37-48 months (34.9\%) among HIVinfected (36.8\%), and outpatients (27.4\%). In unadjusted analysis, age, HIV status and patient type were individually associated with parasite infection. Compared to children younger than 13 months, children in age groups $13-24,25-36,37-48$ and 49-60 months had significantly higher infection with any parasite, (OR, 1.69, 95\% CI, 1.292.20, $\mathrm{p}<0.001),(\mathrm{OR}, 1.87,95 \% \mathrm{CI}, 1.41-2.47, \mathrm{p}<0.001)$, (OR, 2.34, 95\% CI, 1.70-3.23, p < 0.001), (OR, 1.91, 95\% CI, 1.29-2.84, $\mathrm{p}<0.001$ ), respectively. Children who were HIVinfected were more likely to be infected with any parasite (OR, 1.75, 95\% CI, 1.35-2.27, $\mathrm{p}<0.001$ ), while inpatients were less likely to get infected with any parasite than outpatients, (OR, 0.68, 95\% CI, 0.53-0.86, p<0.001), (Table 5). In adjusted analysis, age and HIV status remained significantly associated with parasite infection while patient type was not. Children in age groups 13-24, 25-36, 37-48 and 49-60 months had significantly higher infection with any parasite than children below 13 months old, (adjusted odds ratio (AOR), 1.72, 95\% CI, 1.30-2.29, $\mathrm{p}<0.001$ ), (AOR, 2.01, 95\% CI, 1.46-2.76, $\mathrm{p}<0.001$ ), (AOR, 
Table 3 Associations between patient characteristics and parasitic infection for children aged 5 years and below with diarrhoea in a study of intestinal parasites in urban poor, Nairobi, January 2010 to December 2011

\begin{tabular}{|c|c|c|c|c|c|c|c|}
\hline \multirow{2}{*}{ Patient characteristics } & \multirow{2}{*}{ Cryptosporidium spp. (\%) } & \multicolumn{3}{|c|}{ Crude } & \multicolumn{3}{|c|}{ Adjusted } \\
\hline & & OR & $95 \% \mathrm{Cl}$ & $\mathrm{p}$-value & AOR & $95 \% \mathrm{Cl}$ & $\mathrm{p}$-value \\
\hline Total & 187/2112(8.9) & - & - & - & - & - & - \\
\hline \multicolumn{8}{|l|}{ Gender } \\
\hline Male (ref) & $99 / 1116(8.9)$ & 1.0 & - & - & 1.0 & - & - \\
\hline Female & 88/996(8.8) & 0.99 & $0.74,1.34$ & 0.977 & 1.03 & $0.75,1.42$ & 0.864 \\
\hline \multicolumn{8}{|l|}{ Age group ${ }^{1}$} \\
\hline 0 to 12 months (ref) & 76/758(10) & 1.0 & - & - & 1.0 & - & - \\
\hline 13 to 24 months & $75 / 528(14.2)$ & 1.49 & $1.06,2.09$ & $0.023^{*}$ & 1.90 & $1.31,2.75$ & $0.001^{*}$ \\
\hline 25 to 36 months & 23/408(5.6) & 0.54 & $0.33,0.87$ & $0.011^{*}$ & 0.89 & $0.52,1.52$ & 0.681 \\
\hline 37 to 48 months & $6 / 241(2.5)$ & 0.23 & $0.98,0.53$ & $0.001^{*}$ & 0.39 & $0.16,0.93$ & $0.034^{*}$ \\
\hline 49 to 60 months & $6 / 148(4.1)$ & 0.38 & $0.16,0.89$ & $0.025^{*}$ & 0.59 & $0.24,1.40$ & 0.245 \\
\hline \multicolumn{8}{|l|}{ HIV status ${ }^{2}$} \\
\hline Negative (ref) & 117/1598(7.3) & 1.0 & - & - & 1.0 & - & - \\
\hline Positive & $59 / 302(19.5)$ & 3.07 & $2.19,4.32$ & $<0.001^{*}$ & 2.96 & $2.07,4.21$ & $<0.001^{*}$ \\
\hline \multicolumn{8}{|l|}{ Patient type } \\
\hline Outpatients (ref) & 105/1577(6.7) & 1.0 & - & - & 1.0 & - & - \\
\hline Inpatients & $82 / 535(15.3)$ & 2.54 & $1.87,3.45$ & $<0.001^{*}$ & 1.91 & $1.33,2.73$ & $<0.001^{*}$ \\
\hline Seasonality & & & - & - & & & \\
\hline Dry Season (ref) & & 1.0 & - & - & 1.0 & - & - \\
\hline Wet season & & 1.72 & $1.23,2.41$ & $<0.001^{*}$ & 1.45 & $1.01,2.09$ & $0.042^{*}$ \\
\hline
\end{tabular}

KEY: *significant, missing values $1=29 ; 2=212$.

Infection with Cryptosporidium spp.

2.53, 95\% CI, 1.77-3.64, $\mathrm{p}<0.001)$, and (AOR, 1.85, 95\% CI, $1.20-2.85, \mathrm{p}=0.005)$, respectively. HIV-infected children were more likely to get infected with any parasite (AOR, $2.04,95 \%$ CI, 1.55-2.67, $\mathrm{p}<0.001$ ). Infections with any parasite were significantly associated with wet season (AOR, 1.35, 95\% CI, 1.09-1.68, $\mathrm{p}=0.007$ ) (Table 5).

\section{Prevalence of parasites by seasons}

Data from the meteorological department, Nairobi, showed a bimodal distribution of rainfall during the study period with rainy season being experienced between February to May and September to December, with the wettest months being March and November, while the dry season was in

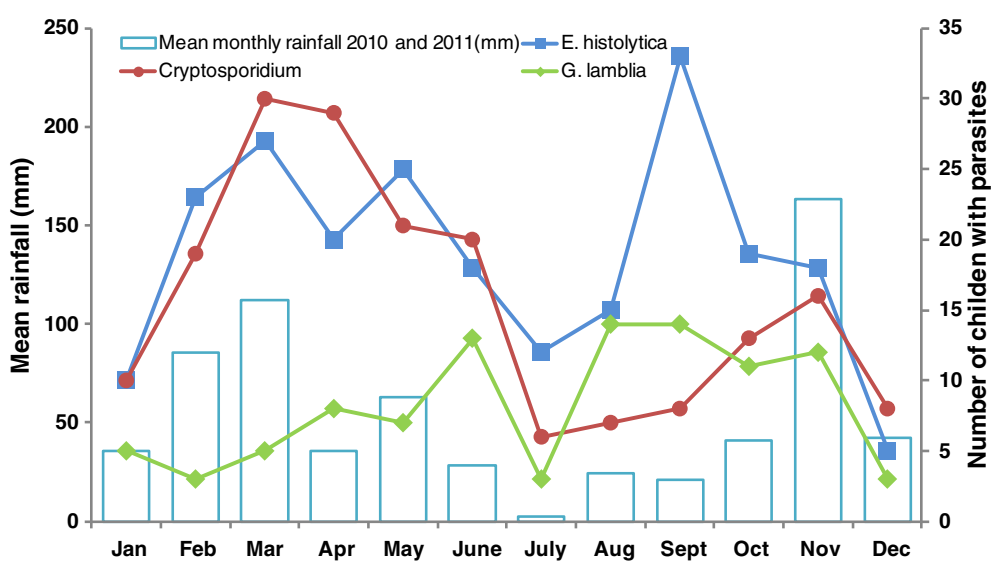

Figure 1 Rainfall in proportion to monthly prevalence of E. Histolytica, Cryptosporidium spp. and G. lamblia. The rainfall patterns in 2010-2011 as received from meteorological department were similar, hence the amounts indicated is the average of the two months in the two consecutive years. 
Table 4 Associations between patient characteristics and parasitic infection for children aged 5 years and below with diarrhoea in a study of intestinal parasites in urban poor, Nairobi, January 2010 to December 2011

\begin{tabular}{|c|c|c|c|c|c|c|c|}
\hline \multirow{2}{*}{ Patient characteristics } & \multirow{2}{*}{ Giardia Iamblia (\%) } & \multicolumn{3}{|c|}{ Crude } & \multicolumn{3}{|c|}{ Adjusted } \\
\hline & & $\overline{\text { OR }}$ & $95 \% \mathrm{Cl}$ & $\overline{p \text {-value }}$ & $\overline{\mathrm{AOR}}$ & $95 \% \mathrm{Cl}$ & $\overline{p \text {-value }}$ \\
\hline Total & $98 / 2112(4.6)$ & - & - & - & - & - & - \\
\hline \multicolumn{8}{|l|}{ Gender } \\
\hline Male (ref) & $56 / 1116(5)$ & 1.0 & - & - & 1.0 & - & - \\
\hline Female & 42/996(4.2) & 0.83 & $0.55,1.26$ & 0.383 & 0.74 & $0.48,1.16$ & 0.193 \\
\hline \multicolumn{8}{|l|}{ Age group ${ }^{1}$} \\
\hline 0 to 12 months (ref) & 10/758(1.3) & 1.0 & - & - & 1.0 & - & - \\
\hline 13 to 24 months & $23 / 528(4.4)$ & 3.41 & $1.61,7.22$ & $0.001^{*}$ & 2.36 & $1.07,5.14$ & $0.031^{*}$ \\
\hline 25 to 36 months & 26/408(6.4) & 5.10 & $2.43,10.67$ & $<0.001^{*}$ & 3.26 & $1.49,7.13$ & $0.003^{*}$ \\
\hline 37 to 48 months & $26 / 241(10.8)$ & 9.05 & $4.30,19.05$ & $<0.001^{*}$ & 5.86 & $2.67,12.89$ & $<0.001^{*}$ \\
\hline 49 to 60 months & 13/148(8.8) & 7.20 & $3.10,16.76$ & $<0.001^{*}$ & 3.95 & $1.59,9.78$ & $0.003^{*}$ \\
\hline \multicolumn{8}{|l|}{ HIV status $^{2}$} \\
\hline Negative (ref) & 78/1598(4.9) & 1.0 & - & - & 1.0 & - & - \\
\hline Positive & 12/302(4) & 0.81 & $0.43,1.50$ & 0.497 & 1.02 & $0.54,1.93$ & 0.946 \\
\hline \multicolumn{8}{|l|}{ Patient type } \\
\hline Outpatients (ref) & 91/1577(5.8) & 1.0 & & & 1.0 & & \\
\hline Inpatients & $7 / 535(1.3)$ & 0.22 & $0.10,0.47$ & $<0.001^{*}$ & 0.41 & $0.17,1.00$ & $0.049^{*}$ \\
\hline Seasonality & & & - & - & & & \\
\hline Dry Season (ref) & & 1.0 & - & - & 1.0 & - & - \\
\hline Wet seas & & 0.60 & $0.40,0.91$ & $<0.015$ & 0.79 & $0.51,1.21$ & -0.280 \\
\hline
\end{tabular}

KEY: *significant, missing values $1=29 ; 2=212$.

Infection with Giardia lamblia.

June to August, and December to January. Frequencies of parasite infections followed this bimodal distribution with highest prevalence being observed between March and May and September to November, and least infections observed in July, which was the driest month (Figure 1).

\section{Discussion}

In this cross-sectional study intestinal parasitic infections were frequent and high proportions of polyparasitism were reported, whereby infections with E. histolytica/dispar, and G.lamblia were higher among outpatients than inpatients (13.8\% vs $1.3 \%$ and $5.8 \%$ vs $1.3 \%)$ respectively, while infection with Cryptosporidium spp. was higher among inpatients than outpatients $(15.3 \%$ vs $6.7 \%)$ respectively. These were the most common enteric parasites associated with diarrhoea in the study population. This is in agreement with an earlier study carried out in Kenya where these three were the most commonly isolated parasites [32]. Higher prevalence has been reported among children in the urban slums of Karachi, Pakistan, where prevalence of $52.8 \%$ was reported [33] and also in children in urban Amman, Jordan, which was at 78\% [34]. The high prevalence of intestinal parasitic infections in these urban slum settings is linked to lack of sanitation, lack of access to safe water and improper hygiene; therefore they occur wherever there is poverty. The prevalence of helminths reported in this study was lower than that of protozoa. This could be attributed to the age of the study population which was less than five years, as reported in other similar studies [35-37]. The intestinal parasitic infections were found to be associated with age with most infections occurring in children aged 24 months and above, and significantly increase with age, with children aged 37- 48 months (34.9\%) more likely to present with intestinal parasitic infections, AOR,1.77,CI,1.77-3.64,p $<0.001$, than other age groups. This has also been observed by Nyantekye [38] in children in Ethiopia, Moyo et al. [39] in Tanzania, as well as in Kenya by Thiongo et al. [40]. This could be either due to higher rates of transmission or accumulative parasites over time. In Kenya,1.5 million persons are living with HIV, 13.3\% being children [41]. Intestinal parasitic infections are among the leading causes of mortality and morbidity among patients infected with HIV and, specifically, gastrointestinal protozoa which cause significant morbidity in children and are opportunistic infections in HIV/ AIDS patients [21,22,42]. In our study population $36.8 \%$ of HIV infected children had parasitic infections as compared to $24.9 \%$ HIV negative children, with 
Table 5 Associations between patient characteristics and infection with any parasite from a study of intestinal parasites in children aged in urban poor, Nairobi, 2010-2011

\begin{tabular}{|c|c|c|c|c|c|c|c|c|}
\hline \multirow[t]{2}{*}{ Patient characteristics } & \multicolumn{2}{|l|}{ Any parasite (\%) } & \multicolumn{3}{|l|}{ Crude } & \multicolumn{3}{|c|}{ Adjusted } \\
\hline & & & $\overline{O R}$ & $95 \% \mathrm{Cl}$ & $\overline{p \text {-value }}$ & $\overline{A O R}$ & $95 \% \mathrm{Cl}$ & p-value \\
\hline Total & $541 / 2112(25.6)$ & & - & - & - & - & - & - \\
\hline \multicolumn{9}{|l|}{ Gender } \\
\hline Male (ref) & 298/1116(26.7) & & 1.0 & - & - & 1.0 & - & - \\
\hline Female & 243/996(24.4) & 0.89 & $0.73,1.08$ & 0.226 & & 0.86 & $070,1.06$ & 0.169 \\
\hline \multicolumn{9}{|l|}{ Age group ${ }^{1}$} \\
\hline 0 to 12 months (ref) & 141/758(18.6) & 1.0 & - & - & & 1.0 & - & - \\
\hline 13 to 24 months & $147 / 528(27.8)$ & 1.69 & $1.29,2.20$ & $0.001^{*}$ & & 1.72 & $1.30,2.29$ & $<0.001^{*}$ \\
\hline 25 to 36 months & 122/408(29.9) & 1.87 & $1.41,2.47$ & $<0.001^{*}$ & & 2.01 & $1.46,2.76$ & $<0.001^{*}$ \\
\hline 37 to 48 months & $84 / 241(34.9)$ & 2.34 & $1.70,3.23$ & $<0.001^{*}$ & & 2.53 & $1.77,3.64$ & $<0.001^{*}$ \\
\hline 49 to 60 months & 45/148(30.4) & 1.91 & $1.29,2.84$ & $0.001^{*}$ & & 1.85 & $1.20,2.85$ & $0.005^{*}$ \\
\hline \multicolumn{9}{|l|}{ HIV status $^{2}$} \\
\hline Negative (ref) & 398/1598(24.9) & 1.0 & - & - & & 1.0 & - & - \\
\hline Positive & 111/302(36.8) & 1.75 & $1.35,2.27$ & $<0.001^{*}$ & & 2.04 & $1.55,2.67$ & $<0.001^{*}$ \\
\hline \multicolumn{9}{|l|}{ Patient type } \\
\hline Outpatients (ref) & $432 / 1577(27.4)$ & 1.0 & & & & 1.0 & & \\
\hline Inpatients & 109/535(20.4) & 0.68 & $0.53,0.86$ & $0.001^{*}$ & & 0.78 & $0.59,1.03$ & 0.084 \\
\hline \multirow[t]{2}{*}{ Seasonality Dry Season (ref) Wet season 0} & & & - & - & & & & \\
\hline & & 1.01 .19 & $--0.97,1.46$ & - - 0.087 & & 1.01 .35 & $-1.09,1.68$ & $-0.007^{*}$ \\
\hline
\end{tabular}

KEY: ${ }^{\text {significant, missing values } 1=29 ; 2=212 .}$

adjusted odds of 2.04,CI,1.55-2.67,p $<0.001$. Prevalence of intestinal parasitic infections among HIV infected patients were also found to be considerably higher in Malaysia, (37.9\%), [43], Ethiopia (52.6\% and 59.8\%) [44,45] respectively, Nigeria (79.3\%) [46] and Indonesia (84.3\%) [22]. In addition, children admitted to hospital were less likely to be infected with intestinal parasites than those seen at the outpatient clinics $(20.4 \%$ vs $27.4 \%$, AOR, 0.68, CI, 0.59$1.03, \mathrm{p}<0.084)$. It is likely that most of the children admitted in hospital may have been treated elsewhere in outpatient clinics in the community before being admitted in hospital. Significant association between Cryptosporidiosis and HIV infection was evident with HIV positive children being at least three times more likely to be infected with Cryptosporidium spp. (19.5\%) than the HIV negative ones (7.3\%) (AOR, 2.96, 95\% CI 2.07-4.21) $\mathrm{p}<0.001$. Higher findings have been reported in Uganda with prevalence of $73.6 \%$ in HIV infected children. The high percentages recorded in Uganda may be, due to the high sensitivity of the molecular techniques used in the studies, whereas the prevalence rates reported in our study are based on microscopy, which is less sensitive. The prevalence in HIV negative children (7.3\%) was comparable to that reported in Uganda (5.9\%) [47] and also in China (3.0\%) [48]. Cryptosporidiosis was highest among children 13-24 months of age as compared to $0-12$ months agegroup. This is in agreement with earlier reports in Kenyan children [32], and similar observations were made in a study in Gaza [49], but it is in contrast to reports on cryptosporidiosis in children in Egypt, where infection was most common among children less than 12 months of age [50,51]. It is not clear why there are differences in susceptibility to infection by age of children, but this may be due to the prevailing Cryptosporidium spp. endemic in specific areas. Understanding the transmission dynamics warrants further investigation of the Cryptosporidium spp. and subtypes and genotypes in circulation. Most intestinal parasitic infections were observed to be higher among the outpatients than inpatients except infections with Cryptosporidium spp., whose prevalence among outpatients was $6.7 \%$, and this was twice as high in inpatients at $15.3 \%$ and the difference was statistically significant, (AOR, 1.91, 95\% CI $1.33-2.73, \mathrm{p}<0.001)$. This might be attributed to the fact that Cryptosporidium spp is difficult to treat and does not respond to the commonly used antiprotozoal drugs except nitazoxanide [52]. This drug is not readily available especially in resource poor settings, hence the high prevalence of these infections among the inpatients than outpatients $(15.3 \%$ vs $6.7 \%, \mathrm{p}<0.001)$, even though most of these children were already on treatment in the wards. Giardia lamblia and E. Histolytica infections 
increased significantly with age with the most affected age group being the 37-48 months, (10.8\%, AOR, 5.86, CI, 2.67-12.89, $\mathrm{p}<0.001$ and 19.1\%, AOR, 2.55, CI, $1.59-4.13, \mathrm{p}<0.001)$ respectively. Considering that these children live in slum areas where the sanitation is poor, with open sewers, and limited access to clean water, they normally play in the soil which harbours these parasites and are less mindful of important personal hygiene practices such as washing of hands with soap and water before eating, after playing and after visiting the toilets. Giardia cysts are highly resistant to environmental conditions, being able to survive in the environment for long periods of time, [53]. Acknowledging the resilience of these cysts, it is conceivable that protozoan infections are much more frequent in poor settings than estimated, even in the absence of reported outbreaks and epidemiological surveys [54]. G.lamblia was more common among outpatients than inpatients $(5.8 \%$ and $1.3 \%)$ respectively. Similar observations have been made elsewhere in studies on urban children, though with higher prevalence observed [55-57]. Polyparasitism (duo and triple infections) was observed in $12 \%$ of the infected samples, mainly involving $E$. Histolytica with one or two other enteric parasites. This is common and widely reported in children elsewhere [58,59]. Seasonal variations are known to affect the prevalence of a number of infections. Although Tuli and colleagues [60] relate intestinal coccidian infection to seasonal variations, there is paucity of reports on effect of seasonal variations on the prevalence of intestinal parasitic infections. These infections showed bimodal transmission with the highest infection rates of observed during wet months. This has also been reported in Malawi where peak prevalence was observed during rainy season [61], as well as in Nigeria [62]. Rainy season may facilitate conditions and risk factors that predispose people to intestinal parasitic infections. The faeces are washed into nearby streams and open sewers that flow along the shanties in the overcrowded urban informal settlements, and can lead to contamination of drinking water, hence, increased infections and indeed, higher prevalence.

\section{Conclusion}

In conclusion, the magnitude of intestinal parasitic infections among the study population of an urban informal settlement in Nairobi is high in children. Routine examination of stool samples for parasites, including Cryptosporidium could significantly benefit both the HIV infected and uninfected children by contributing to reduce morbidity and improved quality of life.

\section{Competing interests}

The authors have declared that no competing interests exists.

\section{Authors' contribution}

CK,SK,NDJ conceived and designed the study protocol and questionnaires for interviews. CK, EM, NJ conducted interviews, performed data and stool collection and provided laboratory analyses of stool samples. AW and CK did the data analysis. Planning, coordination and supervision of data collection in the field, data entry and cleaning, and writing up of the manuscript was done by $C K$. SK,NDJ, and AW revised the manuscript. The final version of the manuscript was reviewed and approved by all authors prior to submission. All authors read and approved the final manuscript.

\section{Acknowledgements}

I would like to acknowledge financial support from Wellcome Trust programme, Kilifi (strategic award, 084538). The children of Mukuru/Mbagathi and their parents/guardians who participated in the study. Special thanks to the entire field, clinical and laboratory staff of the Kenya Medical Research Institute, Mukuru clinics and Mbagathi District hospital, involved in collation of all the data used in this project. This article is published with permission from the Director, KEMRI.

\section{Author details}

${ }^{1}$ Centre for Microbiology Research, P.O Box 19464-00202, Nairobi, Kenya. ${ }^{2}$ KEMRI Wellcome Trust Research Programme, Kilifi, Kenya. ${ }^{3}$ Kenya Medical Research Institute, Nairobi, Kenya.

Received: 7 February 2013 Accepted: 22 May 2013

Published: 27 May 2013

\section{References}

1. WHO/ UNICEF: Diarrhoea: Why children are still dying and what can be done? WHO/ UNICEF Report; 2009:1-16.

2. Montresor A, Crompton DWT, Bundy DAP, Hall A, Savioli L: Guidelines for the evaluation of soil-transmitted helminthiasis and schistosomiasis at community level: A guide for managers of control programmes. Trans $R$ Soc Trop Med Hyg 1998, 92(4):470-471.

3. WHO: Removing Obstacles to development. Report on Infectious diseases. Geneva Switzerland: World Health Organization bulletin; 1999.

4. Bethony J, Brooker S, Albonico M, Geiger SM, Loukas A, Diemert D, Hotez PJ: Soil-transmitted helminth infections: ascariasis, trichuriasis, and hookworm. Lancet 2006, 367:1521-1532.

5. Amadi B, Mwiya M, Chomba E, Thomson M, Chintu C, Kelly P, Walker-Smith J: Improved nutritional recovery on an elemental diet in Zambian children with persistent diarrhoea and malnutrition. J Trop Pediatr 2005, 51:5-10.

6. Andersen PL: Amebiasis. Ugeskr Laeger 2000, 162(11):1537-1541.

7. Korkes F, Kumagai FU, Belfort RN, Szejnfeld D, Abud TG, Kleinman A, Florez GM, Szejnfeld T, Chieffi PP: Relationship between Intestinal Parasitic Infection in Children and Soil Contamination in an Urban Slum. J Trop Pediatr 2009, 55(1):42-45.

8. Alkhalife IS: Retrospective analysis of intestinal parasitic infections diagnosed at a University Hospital in Central, Saudi Arabia. Saudi Med J 2006, 27(11):1714-1718.

9. Ngui R, Ishak S, Chow SC, Mahmud R, Yvonne ALL: Prevalence and Risk Factors of Intestinal Parasitism in Rural and Remote West Malaysia. PLoS Negl Trop Dis 2011, 5(3):1-7.

10. Albonico M, Montresor A, Crompton DW, Savioli L: Intervention for the control of soil-transmitted helminthiasis in the community. Adv Parasitol 2006, 61:311-48.

11. Angeles G, Lance P, Barden-O'Fallon J, Islam N, Mahbub AQ, Nazem NI: The census and mapping of slums in Bangladesh: design, select results and application. Int J Health Geogr 2009, 8:32-38.

12. Warunee N, Choomanee L, Sataporn P, Rapeeporn Y, Nuttapong W, Sompong S, Thongdee S, Bang-on S, Rachada K: Intestinal parasitic infections among school children in Thailand. Trop Biomed 2007, 24(2):83-88.

13. Al Kilan MK, Dahesh SM, El Taweel HA: Intestinal parasitosis in Nalout popularity, western Libya. J Egypt Soc Parasitol 2008, 38(2):393-8.

14. Mukherjee AK, Chowdhury P, Bhattacharya MK, Ghosh M, Rajendran K, Ganguly S: Hospitalbased surveillance of enteric parasites in Kolkata. BMC Res. Notes 2009, 2:110-113.

15. Appleton CC, Mosala TI, Levin J, Olsen A: Geohelminth infection and reinfection after chemotherapy among slum-dwelling children in Durban. Ann Trop Med Parasitol 2009, 103(3):249-261. 
16. Mumtaz $\mathrm{S}$, Siddiqui $H$, Ashfaq $T$ : Frequency and risk factors for intestinal parasitic infection in children under five years age at a tertiary care hospital in Karachi. J Pak Med Assoc 2009, 59(4):216-219.

17. Brooker S, Clements AC, Bundy DA: Global epidemiology, ecology and control of soil-transmitted helminth infections. Adv Parasitol 2006, 62:221-261.

18. Nissapatorn V: Lessons learned about opportunistic infections in southeast Asia. Southeast Asian J Trop Med Public Health 2008, 39(4):625-641.

19. Okodua M, Adeyeba OA, Tatfeng YM, Okpala HO: Age and sex distribution of intestinal parasites infections among HIV infected subjects in Abeokuta Nigeria. J Health Allied Sci 2003, 4:3-5

20. Mariam ZT, Abebe G, Mulu A: Opportunistic and other intestinal parasitic infections in AIDS patients, HIV seropositive healthy carriers and HIV seronegative individuals in Southwest Ethiopia. E Afr J Pub Health 2008, 5(3):169-172.

21. Ajjampur SS, Sankaran P, Kang G: Cryptosporidium species in HIV-infected individuals in India: an overview. Natl Med J India 2008, 21(4):178-184.

22. Kurniawan A, Karyadi T, Dwintasari SW, Sari IP, Yunihastuti E, Djauzi S, Smith HV: Intestinal parasitic infections in HIV/ AIDS patients presenting with diarrhoea in Jakarta, Indonesia. Trans $R$ Soc Trop Med Hyg 2009, 103(9):892-898.

23. Chunge RN, Nagelkerke N, Karumba PN, Kaleli N, Wamwea M, Mutiso N, Andala EO, Gachoya J, Kiarie R, Kinoti SN: Longitudinal study of young children in Kenya: intestinal parasitic infection with special reference to Giardia lamblia, its prevalence, incidence and duration, and its association with diarrhoea and with other parasites. Acta Trop 1991, 50(1):39-49.

24. Joyce T, McGuigan KG, Elmore-Meegan M, Conroy RM: Prevalence of enteropathogens in stools of rural Maasai children under five years of age in the Maasailand region of the Kenyan Rift Valley. East Afr Med J 1996, 73(1):59-62.

25. Saidi SM, Lijima Y, Sang WK, Mwangudza AK, Oundo JO, Taga K, AAihara M, Nagayama K, Yamahoto H, Waiyaki PG, Honda T: Epidemiological study on infectious diarrhoeal diseases in children in a coastal rural area of Kenya. Microbiol Immunol 1997, 41(10):773-778.

26. Nyarango RM, Peninah AA, Ephantus WK, Nyanchongi BO: The risk of pathogenic intestinal parasite infections in Kisii Municipality, Kenya. BMC Publ Health 2008, 8:237-243.

27. National AIDS and STI Control Programme (NASCOP) and Ministry of Public Health and Sanitation: National guidelines for HIV Counselling and Testing in Kenya. 2nd edition. Kenya: NASCOP,MOPHS; 2010:Pp. 13-14.

28. Sherman G, MD G: Dried Blood Spots Improve Access to HIV Diagnosis and Care for Infants in Low-Resource Settings. JAIDS Journal of Acquired Immune Deficiency Syndromes 2005, 5:615-617.

29. Cheesbrough M: District Laboratory Practice in Tropical Countries. Part 2. Cambridge, UK: Cambridge University Press; 2004:299-329.

30. Casemore DP: Laboratory methods for diagnosing cryptosporidiosis. Broadsheet 128. J Clin Pathol 1991, 44:445-451.

31. Centres for Disease Control (CDC,USA): Epi Info ${ }^{\mathrm{TM}} ; 2004$.

32. Gatei W, Wamae CN, Mbae C, Waruru A, Mulinge E, Waithera T, Gatika SM, Kamwati SK, Revathi G, Hart CA: Cryptosporidiosis: prevalence, genotype analysis, and symptom associated with infections in children in Kenya. Am J Trop Med Hyg 2006, 75:78-82.

33. Mehraj V, Hatcher J, Akhtar S, Rafique G, Beg MA: Prevalence and Factors Associated with Intestinal Parasitic Infection among Children in an Urban Slum of Karachi. PLoS One 2008, 3(11):1-6.

34. Shakkoury WA, Wandy EA: Prevalence of Giardia lamblia infection in Amman, Jordan. Pak J Med Sci 2005, 21(2):199-201.

35. Muniz PT, Ferreira MU, Ferreira CS, Conde WL, Monteiro CA: Intestinal parasitic infections in young children in São Paulo, Brazil: prevalences, temporal trends and associations with physical growth. Ann Trop Med Parasitol 2002, 96(5):503-512.

36. Pullan RL, Bethony JM, Geiger SM, Correa-Oliveira R, Brooker S, Quinnell RJ: Human helminth co-infection: no evidence of common genetic control of hookworm and Schistosoma mansoni infection intensity in a Brazilian community. Int J Parasitol 2010, 40(3):299-306.

37. Bethony J, Chen J, Lin S, Xiao S, Zhan B, Li S, Xue H, Xing F, Humphries D, Yan W, Chen G, Foster V, Hawdon JM, Hotez PJ: Emerging Patterns of Hookworm Infection: Influence of Aging on the Intensity of Necator Infection in Hainan Province, People's Republic of China. Clin Infect Dis 2002, 35(11):1336-1344.
38. Nyantekyi LA, Legesse M, Belay M, Tadesse K, Tadesse K, Manaye K, Macias C, Erko B: Intestinal parasitic infections among under-five children and maternal awareness about the infections in Shesha Kekele, Wondo Genet, Southern Ethiopia. Ethiop J Heal Dev 2011, 186:190.

39. Moyo SJ, Gro N, Matee MI, Kitundu J, Myrmel H, Mylvaganam H, Maselle SY, Langeland N: Age specific aetiological agents of diarrhoea in hospitalized children aged less than five years in Dar es Salaam, Tanzania. BMC Pediatr 2011, 23(11):19-25.

40. Thiongo J, Mucheru O, Muite F, Langat B, Kamau P, Ireri L: Spatial Distribution of Giardia intestinalis in Children up to 5 Years Old Attending Out-patient Clinic at Provincial General Hospital, Embu, Kenya. Res J Parasitol 2011, 6:136-143.

41. UNAIDS: The Kenya AIDS epidemic Update. AIDSINFO, Epidemic update and health sector progress towards Universal Access, Joint United Nations Programme on HIV/AIDS (UNAIDS) and World Health Organization (WHO) 2011:pp12-26

42. Eza D, Cerrillo G, Moore DA: Postmortem findings and opportunistic infections in HIV-positive patients from a public hospital in Peru. Pathol Res Pract 2006, 202:767-775.

43. Asma I, Johari S, Benedict LH, Benedict LHS, AL L: How common is intestinal parasitism in HIV-infected patients in Malaysia? Trop Biomed 2011, 28(2):400-410

44. Getachew H, Afework K, Gemeda E, Demekech D, Endris M, Fusao O: Intestinal Parasitic Infections in HIV/AIDS and HIV Seronegative Individuals in a Teaching Hospital. Ethiopia Jpn J Infect Dis 2004, 57:41-43.

45. Assefa S, Erko B, Medhin G, Assefa Z, Shimelis T: Intestinal parasitic infections in relation to HIV status, diarrhoea and CD4 T-Cell count. BMC Infecti Dis 2009, 18(9):155.

46. Adesiji YO, Lawal RO, Taiwo SS, Fayemiwo SA, Adeyeba OA: Cryptosporidiosis in HIV infected patients with diarrhoea in Osun State southwestern Nigeria. Eur J Gen Med 2007, 4:119-122.

47. Tumwine JK, Kekitiinwa A, Bakeera-Kitaka S, Ndeezi G, Downing R, Feng X, Akiyoshi DE, Tzipori S: Cryptosporidiosis and microsporidiosis in Ugandan children with persistent diarrhoea with and without concurrent infection with the human immunodeficiency virus. Am J Trop Med Hyg 2005, 73:921-925.

48. Chong ZXX: Survey on coinfection with HIV and intestinal parasites in high prevalence of HIV/AIDS, China. Bing Fang Zhi Za Shi 2012, 24(2):168-172.

49. Sallon S, El-Shawwa R, Khalil M, Ginsburg G, El Tayib J, El-Eila J, Green V, Hart CA: Diarrhoeal disease in children in Gaza. Ann Trop Med Parasitol 1994, 88:175-182.

50. Abdel-Messih IA, Wierzba TF, Abu-Elyazeed R, Ibrahim AF, Ahmed SF, Kamal K, Sanders J, Frenck R: Diarrhoea associated with Cryptosporidium parvum among young children of the Nile River Delta in Egypt. J Trop Pediatr 2005, 51(3):154-159.

51. Cegielski JP, Ortega YR, McKee S, Madden JF, Gaido L, Schwartz DA, Manji K, Jorgensen AF, Miller SE, Pulipaka UP, Msengi AE, Mwakyusa DH, Sterling CR, Reller LB: Cryptosporidium, Enterocytozoon, and Cyclospora infections in pediatric and adult patients with diarrhoea in Tanzania. Clin Infect Dis 1999, 28:314-321.

52. Cabada MM, Clinton White A Jr: Treatment of cryptosporidiosis: do we know what we think we know? Curr Opin Infect Dis 2010, 23:494-499.

53. Wallis PM, Erlandsen SL, Isaac-Renton JL, Olson ME, Robertson WJ, Van Keulen H: Prevalence of Giardia cysts and Cryptosporidium oocysts and characterization of Giardia spp. isolated from drinking water in Canada. Appl Environ Microbiol 1996, 62(8):2789-2797.

54. Escobedo AA, Almirall P, Alfonso M, Cimerman S, Rey S, Terry SL: Treatment of intestinal protozoan infections in children. Arch Dis Child 2009, 94(6):478-482

55. Fernandez MC, Verghese S, Bhuvaneswari R, Elizabeth SJ, Mathew T, Anitha A, Chitra AK: A comparative study of the intestinal parasites prevalent among children living in rural and urban settings in and around Chennai. J Commun Dis 2002, 34(1):35-39.

56. Rayan P, Verghese S, McDonnel PA: Geographical locations and age affects the incidence of parasitic infestations in school children. Ind. J. Patho\& Microb. 2010, 53(3):498-502.

57. Siwila J, Isaac P, Heidi Larsen E, Mbiko N, Annette O: Seasonal prevalence and incidence of Cryptosporidium spp. and Giardia duodenalis and associated diarrhoea in children attending pre-school in Kafue, Zambia. Trans R Soc Trop Med Hyg 2011, 105:102-108. 
58. Chia-Kwung F, Chien-Wei L, Shu-Yu L, Hosea S, Da-Der J, Chia-Mei C, Jien-Yu J, Ying-Chieh H, Peter Wu-Shou C, Wen-Ta C, Takeshi N, Akiko T, Ya-Hsin H, Chi-Chen T, Lan S-JJ, Jane Chen-Jui C, Jane Chen-Jui C: Prevalence of intestinal parasitic infections among primary schoolchildren in areas devoid of sanitation in northwestern Kingdom of Swaziland, Southern Africa. pathogens and global health 2012, 106:60-62.

59. Lee KJ, Ahn YK, Yong TS: A small-scale survey of intestinal parasite infections among children and adolescents in Legaspi city, the Philippines. Korean J Parasitol 2000, 38:183-185.

60. Tuli L, Gulati AK, Sundar S, Mohapatra TM: Correlation between CD4 counts of HIV patients and enteric protozoan in different seasons - An experience of the tertiary care hospital in Varanasi (India). Biomed Centr Gastroenterol 2008, 8:36.

61. Peng MM, Wilson ML, Holland RE, Meshnick SR, Lal AA, Xiao L: Genetic diversity of Cryptosporidium spp. in cattle in Michigan: implications for understanding the transmission dynamics. Parasitol Res 2003, 90:175-180

62. Akinbo FO, Okaka CE, Omoregie R: Seasonal Variation of Intestinal Parasitic Infections Among HIV-Positive Patients in Benin City, Nigeria. Ethiop J Health Sci 2011, 21(3):191-194.

doi:10.1186/1471-2334-13-243

Cite this article as: Mbae et al:: Intestinal parasitic infections in children presenting with diarrhoea in outpatient and inpatient settings in an informal settlement of Nairobi, Kenya. BMC Infectious Diseases 2013 13:243.

\section{Submit your next manuscript to BioMed Central and take full advantage of:}

- Convenient online submission

- Thorough peer review

- No space constraints or color figure charges

- Immediate publication on acceptance

- Inclusion in PubMed, CAS, Scopus and Google Scholar

- Research which is freely available for redistribution 